\title{
Common Radiological Findings in Children with Suspected Foreign Body Inhalation
}

\author{
Muhammad Junaid ${ }^{1}$, Mansoor Alam², Sahibzada Fawad Khan ${ }^{3}$, Sajid Ali ${ }^{4}$, Khalid Saeed ${ }^{5}$, Hamid Mukhtar ${ }^{6}$ \\ ${ }^{1}$ Assistant Professor, ENT, Head \& Neck Surgery, Khyber Teaching Hospital, Peshawar Pakistan \\ ${ }^{2}$ Registrar, ENT, Head \& Neck Surgery, Khyber Teaching Hospital, Peshawar Pakistan \\ ${ }^{3}$ Associate Professor, ENT, Head \& Neck Surgery, Qazi Husain Ahmed Medical Complex, Nowshera Pakistan \\ ${ }^{4}$ Senior Registrar, ENT, Head \& Neck Surgery, Qazi Husain Ahmed Medical Complex, Nowshera Pakistan \\ ${ }^{5}$ Senior Registrar, ENT, Pak International Medical College, Peshawar Pakistan \\ ${ }^{6}$ Resident, ENT, Head \& Neck Surgery, Khyber Teaching Hospital, Peshawar Pakistan
}

\begin{abstract}
A B S T RACT
Background: Aspirated foreign bodies, an emergency situation, affecting children mostly in the first decade of life, either go undetected, are misdiagnosed or discovered unexpectedly. The purpose of this study was to determine the common radiological findings among children with suspected foreign body inhalation at Khyber Teaching Hospital, Peshawar Pakistan.

Material and Methods: This cross-sectional descriptive study was conducted at the Department of ENT, Khyber Teaching Hospital, Peshawar, from April 2017 to October 2017. All patients $(n=141)$ were subjected to detailed history and clinical examination. $X$ ray chest (AP and lateral views) was performed to detect common radiological findings i.e., radiopaque foreign body (FB), pneumonia, emphysema, atelectasis and air trapping. The age and gender-stratified radiological findings were analyzed using Chi square test to see effect modifications, with $P$-value $<.05$ as statistically significant.

Results: In this study, mean age was $8 \pm 3.563$ years, with most of the children with suspected FB inhalation presenting in the $1-6$ years age group ( $n=82 ; 58 \%)$. Sixty percent children were male while $40 \%$ were female, with emphysema $(28 \%)$ and air trapping (25\%) as the most common radiological findings. Radiopaque FB was detected in $16 \%$ of children on X-ray chest.

Conclusions: Children with suspected foreign bodies should be thoroughly evaluated by both clinical and radiological examination.

Key words: Air Trapping, Atelectasis, Chest X-ray, Emphysema, Pneumonia, Radiopaque Foreign Body.

Authors' Contribution: Correspondence:

${ }^{1}$ Conception; Literature research; Muhammad Junaid manuscript design and drafting; ${ }^{2-6}$ Critical

analysis and manuscript review; Data

analysis; Manuscript Editing.

Article info:

Received: June 29, 2020

Accepted: December 24, 2020

Email: drjunaident@gmail.com
\end{abstract}

Cite this article. Junaid M, Alam M, Khan SF, Ali S, Saeed K, Mukhtar H. Common Radiological Findings in Children with Suspected Foreign Body Inhalation. J Islamabad Med Dental Coll. 2020; 9(4): 280-284. Doi: 10.35787/jimdc.v9i4.608

\section{Introduction}

Foreign body (FB) aspiration remains a public health problem in many countries, attested by the recent
Funding Source: Nil

Conflict of Interest: Nil publications. ${ }^{1}$ Miniature equipment, advances in anesthesia and removal procedure achieved by 
experienced teams, improved the outcome of this medical emergency. ${ }^{2}$

More than $80 \%$ cases of foreign body aspiration occur during early childhood, with a peak incidence between the ages of 10 and 24 months. ${ }^{3-5}$ The absence of molars and premolars and the tendency to put all objects in the mouth predisposes children of this age-group. Symptoms can vary considerably according to the site of the foreign body in the airways. When the foreign body is trapped in the larynx or trachea, respiratory distress or stridor are immediately suggestive of the diagnosis. However, in the majority of cases ( $75 \%$ to $94 \%$ ), the foreign body migrates to the bronchi with no clear and typical symptoms. ${ }^{6}$

Imaging plays an important role in the diagnosis of ingested and aspirated foreign bodies in children and can be crucial to guiding the clinical management of these patients. ${ }^{7}$ Radiographic methods for the diagnosis of tracheobronchial foreign body include chest radiograph, inspiration and expiration chest $\mathrm{x}$-rays, inspiratory and assisted expiratory chest radiographs, fluoroscopy, isotope examination of the lungs and multidetector computed tomography virtual bronchoscopy which is a non-invasive diagnostic tool which provides a three-dimensional view. ${ }^{8,9}$ To demonstrate the consequences of airway obstruction, various radiological techniques are employed to inhale air producing collapse consolidation or to exhale air giving obstructive emphysema. ${ }^{10,11}$

In children with a foreign body in the airway, radiographic features depend on the size, location, duration, and nature of the foreign body. Chest radiography that has been used as the first imaging modality in children suspected for upper airway obstruction may show a variety of findings, including air-trapping, consolidation, atelectasis and bilateral over aeration. ${ }^{12}$
The present study was designed to determine the frequency of various radiological findings among children presenting with suspected foreign body inhalation. The results of this study will be useful in the initial management of FB inhalation as it will delineate the local trend of common radiological findings among children with suspected inhalation of a foreign body.

\section{Material and Methods}

This cross-sectional descriptive study was conducted at the Department of ENT, Khyber Teaching Hospital, Peshawar, from April 2017 to October 2017. The sample size was 141 patients using $15.6 \%$ proportion of atelectasis in patients with FB inhalation, 95\% confidence interval and 6\% margin of error calculated using WHO software. Non probability (consecutive) sampling was done. Children of both genders, aged 01-18 years, with history of FB inhalation in the last 48 hours were included. Those diagnosed with asthma or with previous history of FB removal were excluded from the study. Detailed history, clinical examination and chest $X$ ray (AP and lateral views) was done to detect the common radiological findings of foreign bodies i.e., radiopaque FB, pneumonia, emphysema, atelectasis and air trapping.

Demographic details like name, age, gender, address and contacts were recorded on a pre-designed proforma. The data collected was analyzed in SPSS $v$ 20.0. Mean \pm SD was calculated for continuous variable like age and duration of illness. Frequencies and percentages were calculated for categorical variable like age, gender and common radiological findings. The age and gender-stratified radiological findings were analyzed to see effect modifications. Post stratification was done through Chi square test keeping $P$ value $<.05$ as statistically significant. 


\section{Results}

A total of 141 patients, $85(60 \%)$ male and 56 (40\%) females, and aged $1-18$ years were categorized into age groups, as shown in Table I. Mean age of the study cohort was 8 years \pm 3.56 .

\begin{tabular}{|l|c|c|}
\hline \multicolumn{3}{|c|}{ Table I: Age distribution (n=141) } \\
\hline $\begin{array}{l}\text { Age Groups } \\
\text { (years) }\end{array}$ & Frequency & Percentage \\
\hline $1-6$ & 82 & 58 \\
\hline$>6-12$ & 45 & 32 \\
\hline$>12-18$ & 14 & 10 \\
\hline
\end{tabular}

Table II shows frequency distribution of common radiological findings of suspected foreign body inhalation among the 141 children.

\begin{tabular}{|l|c|c|}
\hline \multicolumn{2}{|c|}{ Table II: Common radiological findings (n=141) } \\
\hline $\begin{array}{l}\text { Radiological } \\
\text { Findings }\end{array}$ & Frequency & Percentage \\
\hline Radiopaque FB & 24 & 16 \\
\hline Pneumonia & 18 & 13 \\
\hline Emphysema & 39 & 28 \\
\hline Atelectasis & 25 & 18 \\
\hline Air trapping & 35 & 25 \\
\hline
\end{tabular}

When age and gender stratification was done with common radiological findings of patients with foreign body inhalation, no significant relationship was observed, as shown in Table III.

\section{Discussion}

Foreign body aspiration is a significant cause of mortality in children for anatomic as well as developmental reasons. The obstruction can lead to difficulties with ventilation and oxygenation, thus resulting in significant morbidity and/or mortality. ${ }^{13}$ It is a serious medical condition and early diagnosis and prompt treatment is mandatory. In a study by Wu et al. on children with FB aspiration admitted to pediatric ICU of Child's Hospital, Zhejiang University, all 28 patients died due to asphyxia and serious complications of foreign bodies inhalation. ${ }^{14}$
In our study, mean age of children was 8 years and $90 \%$ patients were below 12 years of age, with $60 \%$ male and $40 \%$ female children. Common radiological findings included radiopaque FB (16\%), pneumonia (13\%), emphysema (28\%), atelectasis (18\%), and air trapping (25\%).

Brian et al. in a study mentioned plain radiography as the most important modality in evaluation of aspirated foreign bodies. ${ }^{7}$ Oke et al. mentioned foreign body aspiration occurring in $80 \%$ children who were below 15 years of age. ${ }^{15}$ Similar results were observed in another study conducted by Hitter et al. in which mean age was 10 years with $62 \%$ male and $38 \%$ female children. Twenty percent children had radio opaque $\mathrm{FB}, 12 \%$ had pneumonia, $30 \%$ had emphysema, $15 \%$ had atelectasis and $23 \%$ children had air trapping. ${ }^{10}$ Sattar et al. also reported radiopaque $\mathrm{FB}$ in $4.4 \%$, air trapping in $26.7 \%$, pneumonia in $17.8 \%$ and atelectasis in $15.6 \%$ cases of FB aspiration. ${ }^{12}$

In a retrospective study on 2624 children in Algeria, Boufersaoui et al. reported normal-chest $X$ ray in $11.83 \%$ cases of $\mathrm{FB}$ inhalation with obstructive emphysema in $34.26 \%$, atelectasis in $20.35 \%$, pneumonia in $9.48 \%$ and radio opaque $\mathrm{FB}$ in $16 \%$, respectively. ${ }^{16}$

In another retrospective analysis of 67 patients of suspected FB aspiration, admitted to Pediatric Otolaryngology of Medical University of Warsaw, both posteroanterior (PA) and lateral decubitus chest X-rays were done. ${ }^{13}$ The most common radiological findings were emphysema (35\%), mediastinal shift (14\%), atelectasis (12\%) and alveolar consolidations (10.5\%). Almost all of the FBs were radiolucent in nature $(n=56)$. There was one radiopaque FB, which was a pin. According to the authors, chest $\mathrm{x}$-rays may confirm a radiopaque FB, though mostly radiolucent objects are inhaled by children. ${ }^{13}$ 


\begin{tabular}{|c|c|c|c|c|c|c|c|c|c|c|}
\hline \multicolumn{11}{|c|}{ Table III: Age- and gender-stratified radiological findings in suspected cases of FB inhalation } \\
\hline \multirow{3}{*}{ Age Groups (years) } & \multicolumn{10}{|c|}{ Radiological Findings } \\
\hline & \multicolumn{2}{|c|}{ Radiopaque FB } & \multicolumn{2}{|c|}{ Pneumonia } & \multicolumn{2}{|c|}{ Emphysema } & \multicolumn{2}{|c|}{ Atelectasis } & \multicolumn{2}{|c|}{ Air trapping } \\
\hline & Yes & No & Yes & No & Yes & No & Yes & No & Yes & No \\
\hline $1-6$ & 14 & 68 & 10 & 72 & 23 & 59 & 15 & 67 & 20 & 62 \\
\hline$>6-12$ & 8 & 37 & 6 & 39 & 12 & 33 & 8 & 37 & 12 & 33 \\
\hline$>12-18$ & 2 & 12 & 2 & 12 & 4 & 12 & 2 & 12 & 3 & 11 \\
\hline Total & 24 & 117 & 18 & 123 & 39 & 102 & 25 & 116 & 35 & 106 \\
\hline$P$-value ${ }^{*}$ & \multicolumn{2}{|c|}{.95} & \multicolumn{2}{|c|}{.97} & \multicolumn{2}{|c|}{.96} & \multicolumn{2}{|c|}{.94} & \multicolumn{2}{|c|}{.92} \\
\hline Gender & \multicolumn{2}{|c|}{ Radiopaque FB } & \multicolumn{2}{|c|}{ Pneumonia } & \multicolumn{2}{|c|}{ Emphysema } & \multicolumn{2}{|c|}{ Atelectasis } & \multicolumn{2}{|c|}{ Air trapping } \\
\hline & Yes & No & Yes & No & Yes & No & Yes & No & Yes & No \\
\hline Male & 14 & 71 & 11 & 74 & 23 & 62 & 15 & 70 & 21 & 64 \\
\hline Female & 10 & 46 & 7 & 49 & 16 & 40 & 10 & 46 & 14 & 42 \\
\hline Total & 24 & 117 & 18 & 123 & 39 & 102 & 25 & 116 & 35 & 106 \\
\hline$P$-value ${ }^{*}$ & \multicolumn{2}{|c|}{.83} & \multicolumn{2}{|c|}{.94} & \multicolumn{2}{|c|}{.84} & \multicolumn{2}{|c|}{.97} & \multicolumn{2}{|c|}{.97} \\
\hline
\end{tabular}

Lack of awareness of the parents regarding this condition and late presentation of these patients to the ENT department can be regarded as major limitations of this study.

\section{Conclusion}

Children with suspected foreign bodies should be thoroughly evaluated and at least a radiological investigation should be performed before deciding any treatment for its removal.

\section{References}

1. Foltran F, Ballali S, Passali FM, Kern E, Morra B, Passali GC et al. Foreign bodies in the airways: a metaanalysis of published papers. Int J Pediatr Otorhinolaryngol. 2012; 76: S12-S19.

2. Fidkowski CW, Zheng H, Firth PG. The anesthesic considerations of tracheobronchial foreign bodies in children: a literature review of 12.979 cases. Anesth Analg. 2010; 111(4): 1016-1025.

3. Zhijun C, Fugao Z, Niankai Z, Jingjing C. Therapeutic experience from 1428 patients with pediatric tracheobronchial foreign body. J Pediatr Surg, 2008; 43(4): 718-21.

4. Saki N, Nikakhlagh S, Heshmati SM. 25-Year Review of the Abundance and Diversity of Radiopaque Airway Foreign Bodies in Children. Indian J Otolaryngol Head Neck Surg. 2015; 67(3): 261-6.
5. Lena Gordon, Patrik Nowik, Shahla Mobini Kesheh, Marika Lidegran, Sandra Diaz. Diagnosis of foreign body aspiration with ultralow-dose CT using a tin filter: a comparison study. Emerg Radiol. 2020; 27(4): 399-404.

6. Saki N, Nikakhlagh S, Rahim F, Abshirini H. Foreign body aspirations in infancy: a 20-year experience. Int J Med Sci. 2009; 6(6): 322-3.

7. Brian S Pugmire, Ruth Lim, Laura L Avery. Review of Ingested and Aspirated Foreign Bodies in Children and Their Clinical Significance for Radiologists. Radiographics. 2015; 35(5): 1528-38.

8. Cutrone C, Pedruzzi B, Tava G, Emanuelli E, Barion U, Fishetto $D$ et al. The complimentary role of diagnostic and therapeutic endoscopy in foreign body aspiration in children. Int J Pediatr Otorhinolaryngol. 2011; 75(12): 1481-5.

9. Behera G, Tripathy N, Maru YK. Role of virtual bronchoscopy in children with a vegetable foreign body in the tracheobronchial tree. J Laryngol Otol. 2014; 128(12): 1078-83.

10. Hitter A, Hullo E, Durand C, Righini CA. Diagnostic value of various investigations in children with suspected foreign body aspiration: review. Eur Ann Otorhinolaryngol Head Neck Dis. 2011; 128(5): 24852.

11. Tseng HJ, Hanna TN, Shuaib W, Aized M, Khosa F, Linnau KF. Imaging Foreign Bodies: Ingested, Aspirated, and Inserted. Ann Emerg Med. 2015; 66(6): 570-82.

12. Sattar A, Ahmad I, Javed AM, Anjum S. Diagnostic accuracy of chest $\mathrm{x}$-ray in tracheobronchial foreign 
body aspiration in paediatric patients. J Ayub Med Coll Abbottabad. 2011; 23(4): 103-5.

13. Ryczer T, Zawadzka-Głos L, Chmielik M, Szczupak P. The clinical characteristics and radiographic findings in patients with foreign body aspiration. Borgis - New Medicine. 4/2012, s. 105-107.

14. Wu X, Wu L, Chen Z, Zhou Y. Fatal choking in infants and children treated in a pediatric intensive care unit: A 7- year experience. Int J Pediatr Otorhinolaryngol. 2018; 110: 67-9.
15. Oke V, Vadde R, Munigikar P, Bhattarai B, Agu C, Basunia $R$, et al. Use of flexible bronchoscopy in an adult for removal of an aspirated foreign body at a community hospital. J Community Hosp Intern Med Perspect. 2015; 5(5): 285-9.

16. Boufersaoui A, Smati L, Benhalla KN, Boukari R, Smail $\mathrm{S}$, Anik $\mathrm{K}$ et al. Foreign body aspiration in children: experience from 2624 patients. Int J Ped Otorhinol. 2013; 77(10): 1683-8. 